\title{
Comparative Analysis and Treatment Suggestions for Weak Parts and Weak Components of Three-Dimensional Skip-Floor Staggered Shear Wall Structure
}

\author{
LI Pei ${ }^{1, a}$ Liu Jianxin ${ }^{2, b}$ Zhang Yingchun ${ }^{1, c}$ Cai Yingji ${ }^{3, d}$ John Barfoot ${ }^{4, e}$
}

${ }^{1}$ Department of Construction Management, Shanghai Jianqiao University, Shanghai, China

${ }^{2}$ Shanghai Normal University, Shanghai, China

${ }^{3}$ Shanghai Jianwei Cultural Heritage Conservation Tech.Co., Ltd, Shanghai, China

${ }^{4}$ Design and the Built Environment, Southampton Solent University, Southampton, UK

a13816291736@163.com, bljx163@163.com, ㄷ28520505@qq.com, dcaiyingji@shjwqy.com,

ejohn.barfoot@solent.ac.uk

Keywords: skip-floor staggered shear wall structure, ANSYS comparative analysis, treatment suggestions.

Abstract. Based on the elastic-plastic static analysis results of five shear wall structure models by using the finite element software ANSYS, this paper compares the structural cracks developing conditions of the two bottom layers of structural components, analyzes the weak parts, weak components and nodes of the structures, points out that the performance advantages of three-dimensional skip-floor staggered shear wall structure compared to the traditional coupled shear wall structure. Relevant research findings of this paper can provide the technical basis and essential data for promoting the application of skip-floor staggered shear wall structure and the preparation of the technical specifications.

\section{Introduction}

The new three dimensional skip-floor staggered shear wall structure model, eight-layer skip-floor staggered shear wall structure is shown in Fig. 1 model 5, which is composed of four two dimensional skip-floor staggered shear wall structures. The storey height is $3.6 \mathrm{~m}$ and the total height of this building is $28.8 \mathrm{~m}$. The width of the Shear wall is $3.6 \mathrm{~m}$, the span of the coupling beams between the same layer Shear wall is $3.6 \mathrm{~m}$, the spacing between the shear walls is $5.4 \mathrm{~m}$. Seismic fortification intensity is 7 degree. Concrete is of grade C30. The thickness of the shear wall is $180 \mathrm{~mm}$ and the section is reinforced with $\varphi 14 @ 200$ (two-way reinforcement). Given the section of beams of width 300 $\mathrm{mm}$ and depth $600 \mathrm{~mm}$ and the longitudinal reinforcement is $2 \varphi 22$ and lateral ties is $\varphi 10 @ 200$. The section of columns depth is $600 \mathrm{~mm}$ and width is also $600 \mathrm{~mm}$ and the longitudinal reinforcement is $4 \varphi 22$ and lateral ties is $\varphi 10 @ 150$. The thickness of the floor slab is $120 \mathrm{~mm}$ and the section is reinforced with $\varphi 10 @ 200$ (two-way reinforcement). ${ }^{[1]}$

Before static elastic-plastic analysis of the three-dimensional structural model, the single shear walls with different shear wall layouts (model 1 and model 3) were taken from the shear-wall structure of the four- compared with the traditional double-shear wall (model 2). On the basis of model 5, to analyze the effect of symmetrical arrangement and asymmetric arrangement on the structural behavior of the shear wall with cross-section shear wall, a five-span interlaced shear wall structure (model 4 ). 


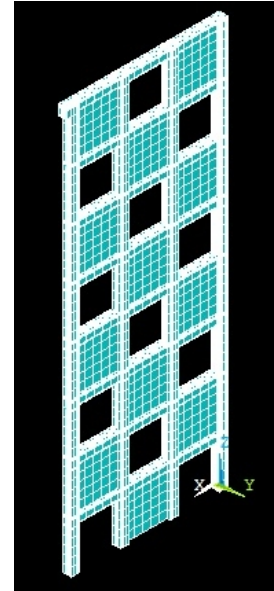

Model 1-

Plane

skip-floor

staggered

shear wall

structure

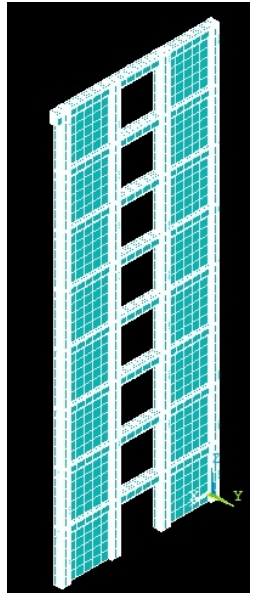

Model 2-

plane

traditional

double-shear

wall structure

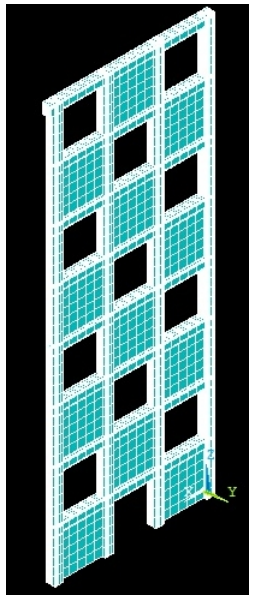

Model 3-

Plane

skip-floor

staggered

shear wall

structure

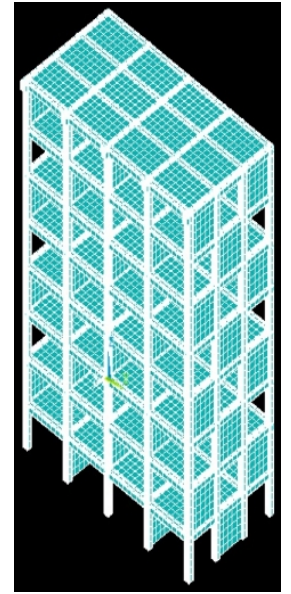

Model 4-

three

dimensional

symmetric

skip-floor

staggered

shear wall

structure

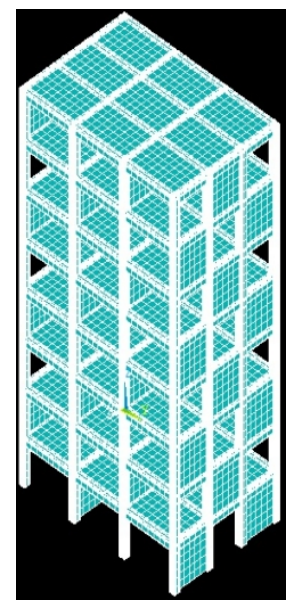

Model 5-

three

dimensional asymmetric

skip-floor

staggered

shear wall

structure

Fig. 1 Five kinds of shear wall structure model

\section{Analysis of Models Cracks Development}

The cracks development of the above five models under monotonic horizontal load is obtained by using ANSYS to conduct the static elasto-plastic analysis, as shown in Fig.2-Fig9.

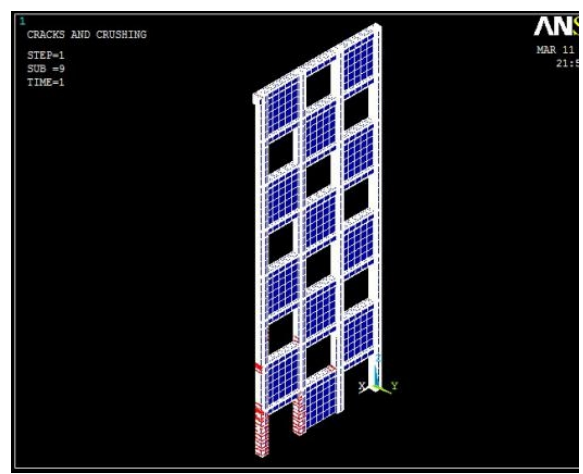

Fig. 2 Structural cracks distribution of model 1

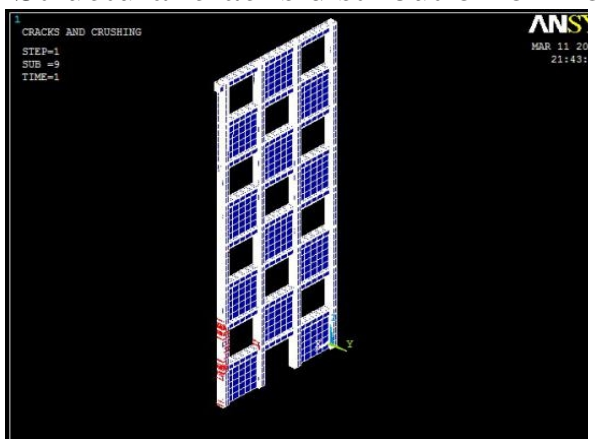

Fig. 4 Structural cracks distribution of model 3

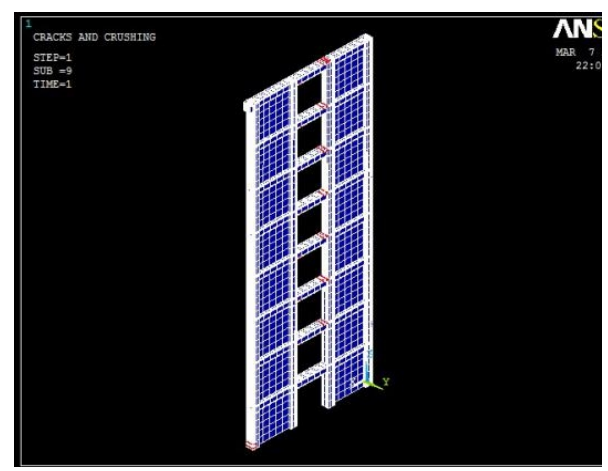

Fig. 3 Structural cracks distribution of model 2

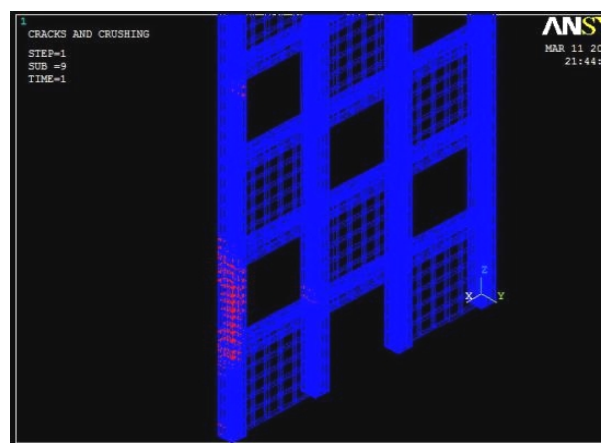

Fig. 5 Cracks detail of model 3 


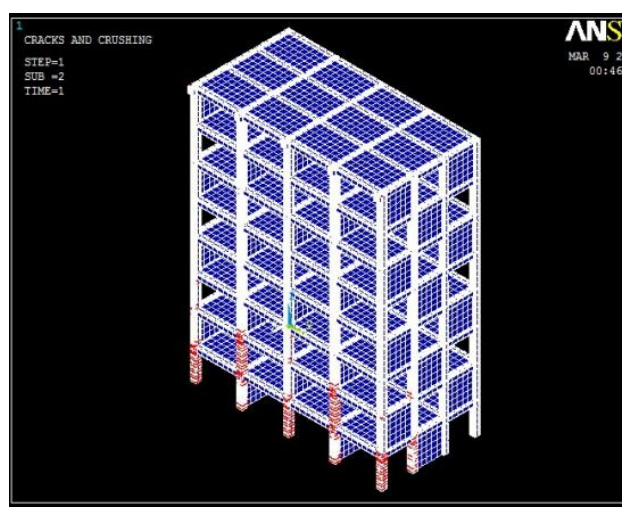

Fig. 6 Structural cracks distribution of model 4

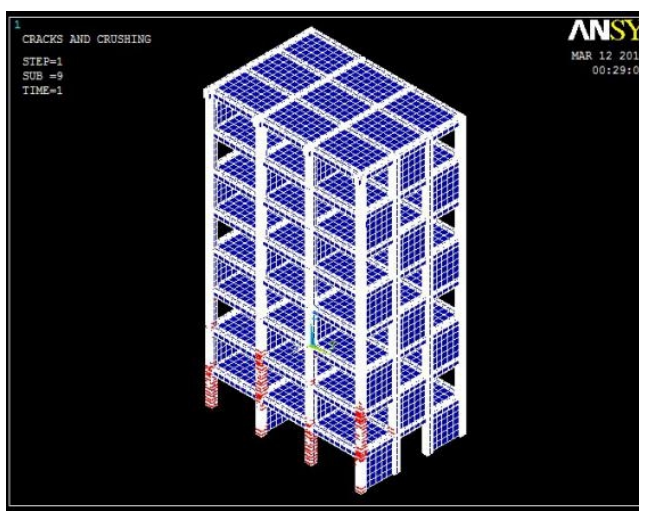

Fig. 8 Structural cracks distribution of model 5

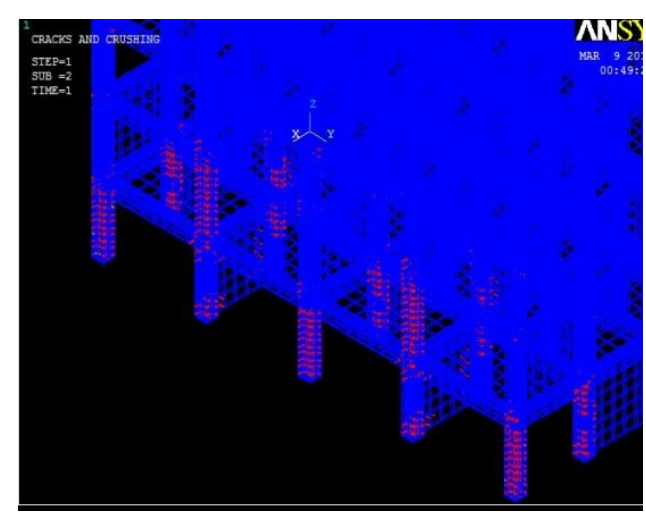

Fig. 7 Cracks detail of model 4

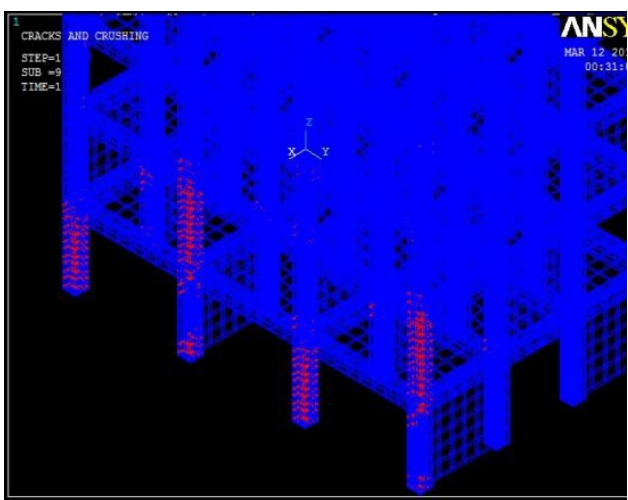

Fig. 9 Cracks detail of model 5

From the above five models of crack distribution analysis shows that:

(1) The cracks of the traditional double-shear wall structure are mainly distributed on the coupling beam, and the cracks of the cross-shear wall structure are mainly distributed in the bottom two frame columns. This is related to the mechanical mechanism of two types of shear wall structures and the distribution of internal forces under horizontal load.

(2) In the model 1 and model 3, the cracks in the bottom side of the model 1 are more concentrated, while the cracks in the model 2 are mainly concentrated in the second column. This indicates that there is a certain concentration of stress in the frame column at the bottom area where the shear wall is not arranged, which is the weak part of the structure.

(3) From the development of cracks in model 4 and model 5, the crack development rule of single shear wall structure is different from that of model 1 and model 3. Similar to the bottom of the region, non-shear wall frame column appears more concentrated cracks.

\section{Analysis of Models Weak Parts}

The lateral displacement of each layer of the four cross-section shear wall structure model can be used to analyze the weak parts of the shear-wall structure by ANSYS. The X-direction displacement curve of skip-floor staggered shear wall structure models, as shown in Fig.10-Fig13. The cross-sectional $\mathrm{X}$-direction displacement curve of skip-floor staggered shear wall structure models are shown in Fig. 14 to Fig. 17. 


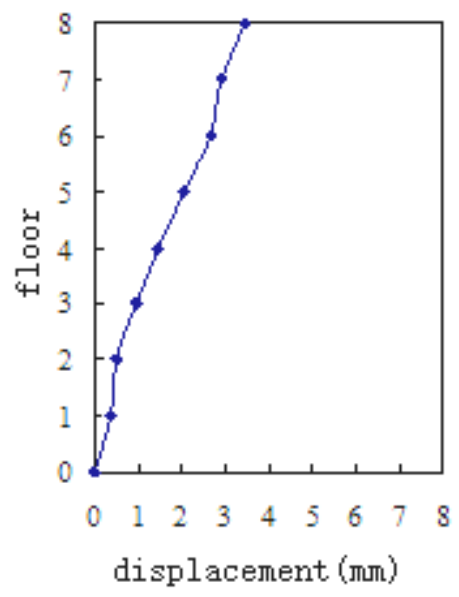

Fig. $10 \mathrm{X}$-direction displacement curve of model 1

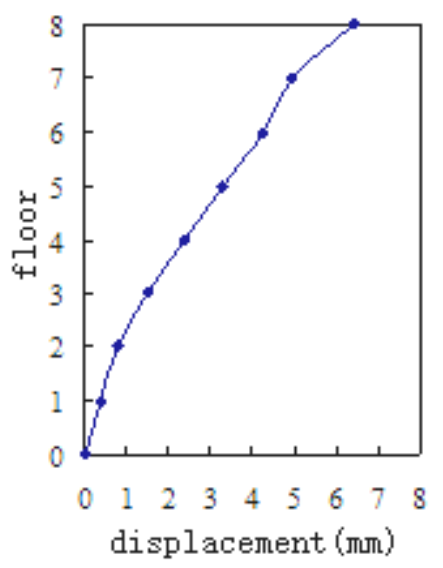

Fig. $12 \mathrm{X}$-direction displacement curve of model 4

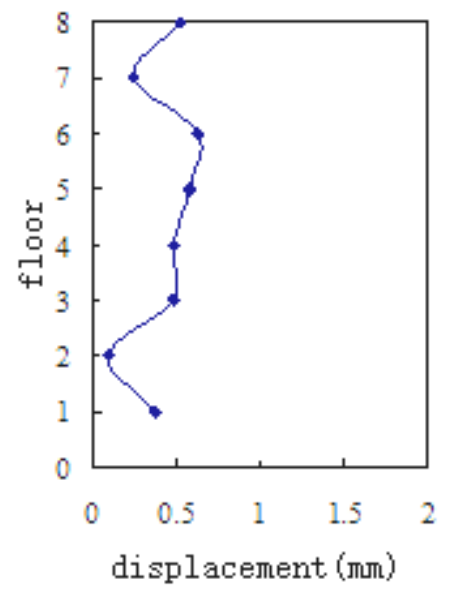

Fig. 14 Cross-sectional X-direction displacement curve of model 1

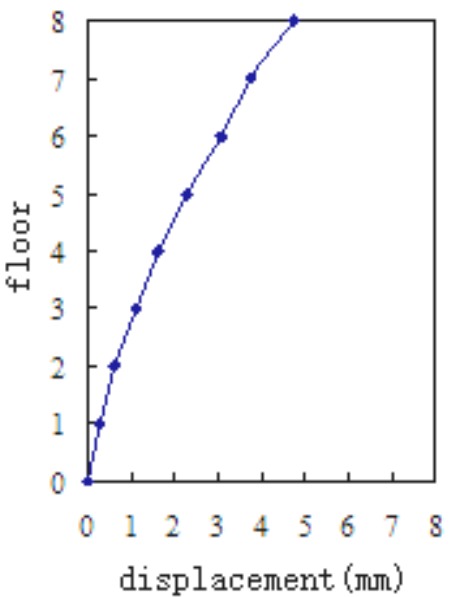

Fig. $11 \mathrm{X}$-direction displacement curve of model 3

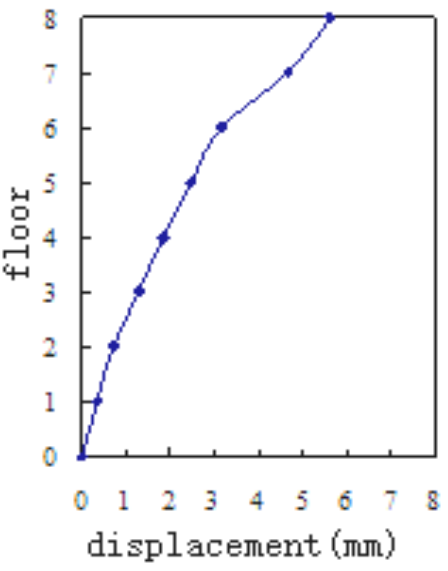

Fig. 13 X-direction displacement curve of model 5

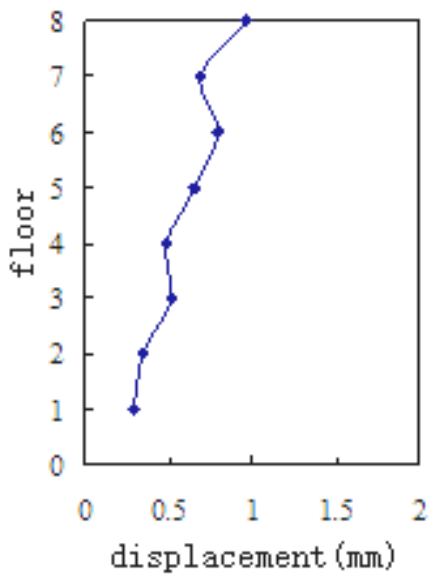

Fig. 15 Cross-sectional X-direction displacement curve of model 3 


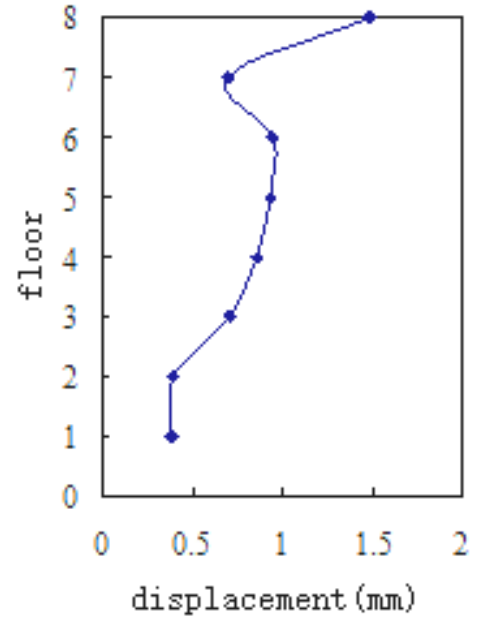

Fig. 16 Cross-sectional X-direction displacement curve of model 4

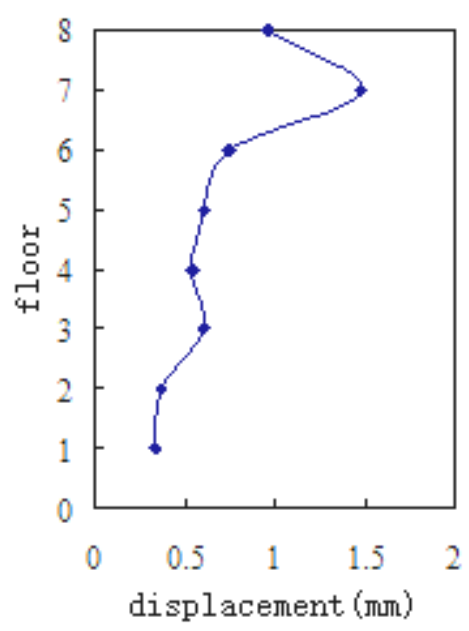

Fig. 17 Cross-sectional X-direction displacement curve of model 5

From the above chart analysis shows that:

(1) The lateral displacement curve of the four-span shear-wall structure model shows that the lateral deformation of the shear-wall structure is more uniform, and the bending deformation of the shear wall is obvious.

(2) The interlaminar lateral displacement of the shear wall structure is more uniform under the horizontal load of the shear wall structure. ${ }^{[2]}$

(3) In the case of floors with large displacement between adjacent stories, it is important to pay attention to the design and take necessary measures to avoid weak structure points. For example, Layer 7th of Model 3 and Model 5.

\section{Treatment Suggestions for Weak Parts and Weak Components}

Based on the current Code for Design of Concrete Structures GB50010, Technical Code for Concrete Structures of High-rise Buildings JGJ3 and Code for Seismic Design of Buildings GB50011, etc., the treatment suggestions for weak parts and weak components of skip-floor staggered shear wall structure are proposed as follows. ${ }^{[3]}$

(1) For the weak parts of the structure, it is recommended to increase the thickness of the shear wall, expand the size of the frame column and enhance the size of the section to improve the anti-lateral capacity of structure weak parts and to avoid structural damage in advance ${ }^{[4]}$

(2) For the weak components of the structure, mainly refers to the location of the frame beam, column and shear wall in the bottom area, it is suggested to enlarge the frame column section size appropriately, increase the longitudinal reinforcement of the frame column, strengthen the two bottom frame beams and columns as well as the horizontal, vertical distribution of shear walls and shear slopes in the shear wall, to avoid serious local structural damages, affecting the force performance of structure.

(3) For the weak nodes, it is suggested to increase the hoop rate in the core area of the joint so that the weak nodes have sufficient safety reserves in the case of compound stress, so as to avoid premature failure.

\section{Conclusions}

Comparative analysis of cracks development and weak parts of skip-floor staggered shear wall structure, Treatment suggestions for weak parts and weak components are proposed in this paper. Relevant research findings can provide the technical basis and essential data for promoting the application of skip-floor staggered shear wall structure and the preparation of the technical specifications. 


\section{Acknowledgements}

This work was financially supported by the Shanghai Municipal Education Commission and Shanghai Jianqiao University.

\section{References}

[1] J Liu, J Shen, M Zhu. Experimental and theoretical studies on seismic performance of the new skip-floor staggered shear wall structure for tall building[J].China Civil Engineering Journal, (2014), in press.

[2] J Liu, Pei Li. Nonlinear Analysis of a New 3D Skip-Floor Staggered Shear Wall Structure[J]. Advanced Materials Research.(2013), p.164-170.

[3] J Liu, H Wang, Pei Li, M Zhu. Experiment Study and Nonlinear Analysis of a New Skip-Floor Staggered Shear Wall Structure for High-Rise Buildings[J].Applied Mechanics and Materials.(2013), p.131-137.

[4] YC Jiang, XW Jin. Study on the Seismic Behavior of New Frame-shear Wall Structure[J].

Science Technology \& Engineering, (2013), in press. 